\title{
Music therapy for emotion regulation skills and better psychological well-being for cancer patients: Making of a therapeutic programme
}

\author{
Jana Duhovska ${ }^{1, *}$ and Inga Millere ${ }^{2}$ \\ ${ }^{1}$ Rīga Stradiņš University, Faculty of Rehabilitation, Psychosocial Support centre of Oncology \\ Centre of Latvia, Riga, Latvia \\ ${ }^{2}$ Rìga Stradiņš University, Faculty of Public Health and Social Welfare, Riga, Latvia
}

\begin{abstract}
Objective of this research is to explore the subjective experience and perceived benefits of 60 cancer patients participating in the music therapy based and Expressive Therapies Continuum and Dialectical Behaviour Therapy informed psychosocial support programme. The data was obtained by means of questionnaire and focus group discussions. All participants $(n=60)$ performed written evaluation of the programme: a) of their overall experience, b) its specific benefits for addressing pain, anxiety as well as social support, emotion regulation and overall quality of life issues, c) its most/least enjoyable/helpful elements. Participants $(n=20)$ of the four focus group discussions, on their turn, explored the specific elements (contents, organisation, instructions, timetable) of the programme to provide the grounds for future amendments. Results reveal that $70 \%$ of participants rated their overall experience as "very valuable" or "valuable", $24 \%$ indicated as "neutral", whereas $6 \%$ admitted that their participation has not led to "substantial gains". The top five benefits included: improved mood, reduced stress, received support, improved communication, coping with negative emotions linked with disease or treatment. Among the most enjoyable and helpful elements, participants emphasized the ones that were linked with the acquired ability to face and survive difficult emotions $(n=43)$, discovering inner strength $(n=58)$, gaining more confidence by acquiring new skills or experience $(n=29)$, gaining connectedness with group and music $(n=32)$, musically beautiful moments and transcendence $(n=58)$ as well as normalization of their experience $(n=50)$. Focus group discussion provided with valuable recommendations regarding the inclusion of psycho-education elements, size of the group, format of task instructions, pace of the work and necessity for balance between the safety and novelty. It can be concluded that participation in the programme positively affected psychological and social well-being of the cancer patients. Results of this research provide valuable input for the further development of the programme - both organisation and content-wise.
\end{abstract}

\section{Introduction}

\subsection{Music therapy in oncology}

Music therapy is the clinical and evidence-based use of music interventions to accomplish individualized goals within a therapeutic relationship by a professional who has completed an

\footnotetext{
* Corresponding author: jana.duhovska@rsu.lv
}

(C) The Authors, published by EDP Sciences. This is an Open Access article distributed under the terms of the Creative Commons Attribution License 4.0 (http://creativecommons.org/licenses/by/4.0/). 
approved music therapy program. Cancer patients and survivors are in need for psychosocial support in order to be able to return to life as normal as possible, and music therapy can be effective to address personal and social outcomes of rehabilitation.

Music therapy is a valuable and evidence-based treatment for patients with cancer $[1,5]$. For example, evidence of significantly decreased anxiety and depression, improved quality of life, and shorter length of hospital stay, are reported via randomized controlled studies [2, 3].

Previous studies have also demonstrated the effectiveness of music therapy during cancer treatment for pain and procedural anxiety, distraction, and increased relaxation [2]. However, there is a need for research on the subjective experience and perceived benefits of cancer patients of music therapy activities to devise the programs that are both effective and motivating.

\subsection{Purpose and background of the study}

Objective of this research is to explore the subjective experience and perceived benefits of 60 cancer patients participating in the music therapy based and Expressive Therapies Continuum and Dialectical Behaviour Therapy informed psychosocial support programme.

The author of this paper is a university researcher and certified music therapist, who developed and implemented the programme, and further investigated the subjective experience of the participants of the programme. Results of this study will be further utilized to develop intervention for randomized controlled study taking place within hospital setting.

\section{Participants and location}

Sixty participants (96\% of them women), mean age 62.75 years, with a diagnosis of cancer (breast cancer in $86 \%$ of cases), participating in a psychosocial rehabilitation programme, were recruited to take part in a set of group music therapy sessions and this study.

The music therapy was delivered as part of a larger programme, tackling both psychological as well as physical effects of the cancer survivorship. Thus, apart from music therapy, participants received group counselling sessions led by clinical psychologist or psychotherapists, participated in various physical activities and received information on various health behaviour topics).

All activities, including music therapy sessions (further - music therapy programme), were delivered in groups (average group size -7.5 participants).

\section{Description of the music therapy programme}

\subsection{Goals and mechanisms of change}

The programme (see Sect. 3.3.), consisting of four 90-minute sessions and led by certified music therapist, based on a set of active and receptive music therapy techniques, each of them having specific topic and goal for development of abilities that were to be strengthened in order to be later transferred to life areas and situations outside the therapeutic setting.

The overall goals of the programme were:

1) to provide the opportunity for experience of well-being (incl., physical well-being, considering pain, fatigue, neuropathies, and residual symptoms),

2) to develop the internal locus of control and self-regulation skills (incl., ability to identify, describe and monitor ones' actual emotional state, and to intentionally change it, if appropriate), as well as 
3) to test and acquire new models of interpersonal relationship (such as pro-activity, ability identify ones' needs, to ask for help or to provide help, ability for setting and executing ones' boundaries).

As to the therapeutic mechanisms, programme relied on the following:

1) giving respect to the unique, individual stories of the participants and normalizing the difficulties, once other people reveal the same or similar experience,

2) providing balance between "the good old" (safe, the comfortable, the familiar) and "the new" (the novelty, letting the control go and allowing oneself to be in uncertainty, in the unknown),

3) utilisation of patients' imagination and helping to recognize and experience their inner resources and self-induced well-being,

4) attention work and mindfulness to prevent the uniform focus (on body, on thoughts about the illness) and to expand the subjective and world experience,

5) creative expression, development of cognitive elasticity or flexibility and openness to experience and some risk,

6) playfulness, being bouncy and able to react.

\subsection{Theoretical framework}

The programme used two theoretical frameworks - Expressive Therapies Continuum having roots in arts therapies, and Dialectical Behaviour Therapy - being one of the psychotherapeutic approaches utilized to address the emotion regulation as skill affecting ones' own well-being as well as relationship with other people.

\subsubsection{Expressive Therapies Continuum}

Expressive Therapies Continuum (ETC)-is a model, based on ideas of an art educator Wictor Lowenfeld and conceptualized by Lusebrink and colleagues [4, 6], that poses the idea that human being is perceiving the world and processing the information in three modes, each with two poles, revealing opposites existing within the mode (See Table 1):

a) motion (kinaesthetic-sensory perception),

b) emotion (perceptual-emotional perception) and

c) thought (cognitive-symbolic perception), as well as

d) creative level or vertical axis intersecting the horizontal levels and possibly presenting at any level or representing the integration of functioning from all levels.

According to research by developers of the framework, optimally functioning person is equally able to function in all the modes, can slide between the poles of each of the mode and can freely integrate the elements from various modes and poles. And vice versa - difficulty or inability to enter specific modes or preferring specific modes above others, can indicate to malfunction and even psycho-pathology $[4,6]$.

This then defines the therapeutic application of the model, namely - purposeful exploration of the "unsafe" functions as well as integration of various functions by offering expressive, creative activity therefore promoting utilisation of various functions of the ETC, and leading to more optimal, integrative functioning of the person.

Originally designed and described within the visually plastic art (therapy) setting, it is now explored for usage in other modalities of art, including music therapy [4], where it can 
Table 1. Expressive therapies continuum.

\begin{tabular}{|c|c|c|c|}
\hline Thought & $\begin{array}{l}\text { Cognitive: thinking, reasoning, } \\
\text { systematizing, verbalizing, } \\
\text { rationalizing, talking }\end{array}$ & \multirow{3}{*}{ 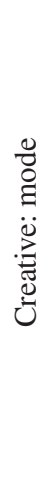 } & $\begin{array}{l}\text { Symbolic: relying on intuition, } \\
\text { previous experience, symbolic } \\
\text { thinking, allowing oneself to be } \\
\text { creative }\end{array}$ \\
\hline Emotion & $\begin{array}{l}\text { Perceptual: having certain form, } \\
\text { structure, repetitive motifs, } \\
\text { having clear background and } \\
\text { foreground, being emotionally } \\
\text { contained, and controlled in a way }\end{array}$ & & $\begin{array}{l}\text { Affective: being taken away by } \\
\text { emotions, emotional expression, } \\
\text { exploration of emotional states }\end{array}$ \\
\hline Motion & $\begin{array}{l}\text { Kinaesthetic: rhythmic, } \\
\text { movement - simple motor } \\
\text { expressions, authentic energy, } \\
\text { release of energy }\end{array}$ & & $\begin{array}{l}\text { Sensory: sense by sensual - smell, } \\
\text { touch }\end{array}$ \\
\hline
\end{tabular}

be applied both for assessment and therapy planning instrument as the criteria provided within the framework provide a rather clear information to identify:

1) the predominance of one or more levels of ETC, therefore revealing the individual's strengths (or lack of difficulty, and of pathology) that can serve as an entry point or the secure base to start the therapy from or to return to when processes become too challenging,

2) the missing levels or poles, therefore revealing the individual's deficits that could or should be elaborated during the therapeutic process to attain more optimal functioning.

As to the planning of the therapy process, Lusebrink $(2014,2010)$ points out that, depending on the needs and pathology of the individual, treatment can include either stepwise bottomup or top-down transitions between the ETC levels or horizontal transformations with each level, and, to attain the optimal functioning characterized by flexible and versatile activity, purposeful integration of various ETC functions can be successfully organized via artistic activities, including techniques based on music - be it listening, free play or structured activity [4].

\subsubsection{Dialectical Behaviour Therapy}

Dialectical Behaviour Therapy (DBT) - a combination of cognitive-behavioural and mindfulness components that uses a skills-training approach to change problematic behaviour patterns related to emotional deregulation [9]. The skills training in DBT addresses four areas $[7,9]$ :

1) mindfulness - being aware of the present moment without the judgement, trying to identify, analyse the situation and then to choose the reaction (as the opposite to reacting with emotions),

2) being effective interpersonally - becoming more assertive in a relationship (for example, expressing needs and saying "no") while still keeping that relationship positive and healthy. This happens by learning to listen and communicate effectively, deal with difficult people, and respect yourself and others,

3) development of emotion regulation skills - observing and describing (knowing the triggers, defining the emotion), intentionally seeking for positive experiences so that negative emotions are outnumbered by positive ones, 
Table 2. Elements of therapeutic programme.

\begin{tabular}{|c|c|c|c|}
\hline $\begin{array}{l}\text { Number of session } \\
\text { and overall topic }\end{array}$ & $\begin{array}{l}\text { Music therapy } \\
\text { activities }\end{array}$ & $\begin{array}{l}\text { ETC-related } \\
\text { elements }\end{array}$ & DBT-related elements \\
\hline 1. Tuning in & $\begin{array}{l}\text { a) Music listening and } \\
\text { analysis [7] } \\
\text { b) Analysis of novel } \\
\text { and familiar } \\
\text { instruments [7] } \\
\text { c) Playing instruments } \\
\text { individually and in } \\
\text { structured group } \\
\text { improvisation }\end{array}$ & $\begin{array}{l}\text { a) Affective, } \\
\text { Cognitive, Symbolic } \\
\text { b) Affective, } \\
\text { Kinaesthetic, Sensory, } \\
\text { Symbolic } \\
\text { c) Kinaesthetic, } \\
\text { Perceptive, Cognitive }\end{array}$ & $\begin{array}{l}\text { Mindfulness: to be } \\
\text { consciously aware of } \\
\text { the present moment: } \\
\text { a) Non-judging } \\
\text { b) Beginners mind } \\
\text { c) Suspending } \\
\text { judgment }\end{array}$ \\
\hline 2. $\mathrm{Me}$ & $\begin{array}{l}\text { Voice work [8]: } \\
\text { a) Singing portraits } \\
\text { and their stories from } \\
\text { photography } \\
\text { b) One's voice work - } \\
\text { having one's voice, } \\
\text { presenting oneself and } \\
\text { one's story verbally } \\
\text { and musically to others }\end{array}$ & $\begin{array}{l}\text { a) Affective, } \\
\text { Cognitive, Symbolic } \\
\text { b) Cognitive, } \\
\text { Symbolic, Sensory }\end{array}$ & $\begin{array}{l}\text { Emotion regulation: to } \\
\text { become aware of the } \\
\text { triggering situations } \\
\text { and to develop } \\
\text { emotion regulation } \\
\text { skills }\end{array}$ \\
\hline 3. Me and others & $\begin{array}{l}\text { Giving and receiving } \\
\text { help, relying on the } \\
\text { other and to be } \\
\text { reliable to the other: } \\
\text { a) Work in pairs, } \\
\text { b) Work in group }\end{array}$ & $\begin{array}{l}\text { a) Affective, } \\
\text { Cognitive, } \\
\text { Kinaesthetic, } \\
\text { Perceptive } \\
\text { b) Symbolic, } \\
\text { Affective }\end{array}$ & $\begin{array}{l}\text { Distress tolerance: } \\
\text { managing impulsive } \\
\text { behaviours: acquiring } \\
\text { techniques for } \\
\text { distress tolerance } \\
\text { skills }\end{array}$ \\
\hline 4. Us & $\begin{array}{l}\text { Group improvisation, } \\
\text { gradually led from } \\
\text { fully structured to the } \\
\text { semi-structured } \\
\text { improvisation on the } \\
\text { topic of the safe space }\end{array}$ & $\begin{array}{l}\text { All the elements, } \\
\text { integrative activity }\end{array}$ & $\begin{array}{l}\text { Being effective } \\
\text { interpersonally: } \\
\text { assertiveness training } \\
\text { in group activities }\end{array}$ \\
\hline
\end{tabular}

4) acquiring of techniques (imagery, relaxation, radical acceptance, half-smile, etc.) for distress tolerance skills to get through the crisis situations not making them worse (via emotional outburst, for example) and to accept situation as it is.

DBT and music therapy both are well documented in literature for the treatment of individuals with mental health needs, but there are very limited resources on the use of the combination of DBT and music therapy. So, this research provided grounds for both creating and researching the practical application and effect of such a rather novel combination.

\subsection{An overview of the programme}

The therapeutic programme, designed by the music therapist (the researcher) to meet the therapeutic goals that were discussed earlier and to include the elements of the ETC and the DBT, was implemented in a manner that initially required rather passive participation, but the level of the participation grew with each subsequent session, supposed to have the peak activity and involvement during the fourth session. See the overview of the programme in Table 2. 


\section{Method}

To explore the subjective experience and perceived benefits of participants in the programme, all the participants $(n=60)$ were asked to fill in the Music therapy evaluation form, consisting of 6 sections that were devised for getting an insight both about the overall experience as well as about the specific parts in the contents and organization of the programme that were helpful and comfortable, and that were not. As well, participants were asked to indicate on specific areas of their well-being that were particularly affected by the programme. The questions included were the following:

1) Please, provide a general evaluation of experience in the programme. (A Likert scale was provided: from -2 (no benefit at all) to 0 (neutral) to +2 (very valuable)).

2) Was music therapy helping in any of these matters? Please, tick all that is appropriate in your situation. (A list of possible gains and line for "other" was provided. The gains provided: decreased stress, decreased anxiety, increased overall mood, helped to cope with negative emotions, that are related to the cancer situation, provided support, helped in building relationship, enhanced communication skills, taught new skills).

3) What or which part of the music therapy programme was most helpful or meaningful for you? Why? (Open-ended question).

4) What or which part of the music therapy programme was least helpful or meaningful for you? Why? (Open-ended question).

5) Will you be able to use any of the experiences or skills gained during music therapy in your daily life? Which one? (Open-ended question).

6) Please describe which particularly memorable moments (if there were any) you experienced during the music therapy programme. (Open-ended question).

To explore the organisational aspects of the programme in order to be able to organize further improvements (if necessary), 20 participants were invited for the focus group discussion, results of which provided information on such elements of the programme as contents, organisation, instructions and timetable.

\section{Results and interpretation}

\subsection{Results from music therapy evaluation form}

Results obtained anonymously in written form via Music therapy evaluation form revealed that $70 \%$ of participants considered their experience as very valuable or valuable, $24 \%$ believed it has been "neutral", $6 \%$ of participants believed that participation in the programme gave no benefit to them. Let us further take a closer look at the subjective experience and special moments as revealed by the written form.

As to most and least helpful parts of the programme, answers could be clustered in the themes, see Table 3. Considering parts and experience in the programme that were the most helpful or meaningful, participants referred to such phrasing as music therapy group work "provided an outlet for difficult emotions", "provided feelings of being understood and not judged", "provided opportunity for self-care", "opened buried feelings and expressed them to let them go", "felt good to be in group and not alone", "felt difficult, but also good to overcame my fear", and similar. Considering parts and experience in the programme that were the least helpful and meaningful, participants referred to such as "sometimes the tasks seemed too difficult", "for those, who are not musicians, it was rather easy to look stupid and fail", "it was really uncomfortable - to be like on stage", "it was too difficult to again analyse my situation", and similar. 
Table 3. The least and the most helpful parts of the programme.

\begin{tabular}{|l|l|}
\hline Question/Topic & Themes \\
\hline $\begin{array}{l}\text { What or which part of the music } \\
\text { therapy programme was most helpful } \\
\text { or meaningful for you? }\end{array}$ & $\begin{array}{l}\text { Togetherness }(n=54) \\
\text { Overcoming ones' internal limitations }(n=43) \\
\text { Discovering and training ones' imagination }(n=43) \\
\text { Using ones' voice }(n=40) \\
\text { Novel experience and opportunity to learn }(n=29)\end{array}$ \\
\hline $\begin{array}{l}\text { What or which part of the music } \\
\text { therapy programme was least helpful } \\
\text { or meaningful for you? }\end{array}$ & $\begin{array}{l}\text { Difficult topics (illness, future) }(n=23) \\
\text { Fear of failure, of looking funny, unprofessional in front } \\
\text { of the group }(n=13) \\
\text { Overcoming ones' internal limitations }(n=12)\end{array}$ \\
\hline
\end{tabular}

As to particularly memorable moments, among the top ones participants referred to such as power of imagination and visualisation $(n=58)$, musically beautiful (aesthetic) moments $(n=52)$, also connectedness via music [with other people, feeling as part of something that is meaningful]. $83.3 \%$ of participants also emphasized opportunity to see that other people undergo the same difficulties [universality], so they could feel "more normal" [normalisation]. Several participants referred to specifically musical part of the programme, e.g. "I realized music can be used for spiritual support", "musical instruments and sounds served to portrait people and experience", "playing new instruments was like a metaphor for trying new things", "music was the vehicle for accessing my own imagination - a resource that is always accessible, but usually is used in negative manner [anticipating negative outcomes]".

Regarding experiences and skills that might be further used in their life, participants emphasized such as "attention work - being aware of the moment and not judgmental" $(n=47)$, "deliberate utilisation of music for needs such as activation and relaxation" $(n=45)$, "asking for what is needed to myself" [e.g. help], "more energetic position in everyday life" $(n=18)$, "curiosity and zest for new things" $(n=18)$. Of participants, $20 \%$ reveal that they are now interested to enter musical activities [playing instrument, joining choir].

\subsection{Results from focus group discussion}

The goal of focus group discussions was to elicit recommendations for further work, and the questions of inquiry were directed towards the contents, organisation, instructions, and timetable of the programme. This resulted in a list of valuable suggestions. The top 5 of them are such as inclusion of more psycho-educational elements (e.g. impact of stress on overall health; strategies of coping with stress; practicing and impact of gratitude; neuroplasticity), which go hand in hand with the need "to explain the purpose of the task" (to provide participants with greater sense of control and willingness to invest more energy, as they anticipate that (otherwise) playful activity might bring to valuable results).

Discussion also revealed the "need for formation of smaller groups" (the mean group size was 7.5) as well as "provision of written instructions to the tasks".

The fiercest discussion evolved around the idea whether therapy should provide only with pleasant moments, or it is healthy and even healing to also go through the challenge and difficulties. As the results obtained via written form revealed, some participants found participation in the programme uncomfortable - partly due to the need to be engaged in the (musical) activities that seemed to challenge their image in front of others and did not foster their sense of competence. However, there is other side to this, and that is "overcoming one's own limitations" - one of the experiences, considered as the most meaningful, helpful and 
leading to the overall activation and zest for new things and life. So, the conclusion of the focus group on this matter was to "provide balance between the familiar and challenge", namely - to organize the work in a manner that provides both some challenge and at the same time does not threaten the sense of agency.

\section{Conclusions}

1. Music therapy in group setting can be helpful for addressing emotion regulation skills and better psychological well-being for cancer patients.

2. Realizing the universality of (cancer related) difficulties (as experienced by others) and experience of musical togetherness in group, as well as discovering inner resource of imagination and self-regulation have been the source of the most meaningful moments of the participants. However, self-doubt and sense of incompetence while entering the music-based tasks, as well as addressing the topics directly related to illness, have caused the most difficulties.

3. The program should provide more psycho-education elements as well as inform the participants about the purpose of the task, and provide with written instructions.

4. To reduce the resistance stemming from fear of failure, there is need for careful planning to balance between the tasks that provide support and tasks that provide challenge.

\section{References}

[1] J. Allen, Guidelines for Music Therapy Practice in Adult Medical Care (New Braunfels, Barcelona Publishers, 2013)

[2] J. Bradt, C. Dileo, L. Magill, A. Teague, Cochrane Database of Systemat. Rev. 8, CD006911 (2016)

[3] C. Dileo, J. Soc. Integrat. Oncol. 4(2), 67-70 (2006)

[4] J. Duhovska, V.B. Lusebrink, K. Mārtinsone, Assessment and therapeutic application of the Expressive Therapies Continuum in music therapy: The case of Anna with cancerrelated depression edited by A. Zubala, V. Karkou, Arts therapies in the treatment of depression (Routledge, 2018), pp. 241-255

[5] A.L. Dvorak, Canadian J. Music Ther. 21(1) (2015)

[6] L.D. Hinz, Expressive therapies continuum: A frameworkfor using art in therapy (New York, Routledge, 2009)

[7] T. Lesiuk, Healthcare 4, 53 (2016). DOI: 10.3390/healthcare4030053

[8] J. ØrnholtBøtker, Voice work within educational setting edited by Duhovska, J. (sast) Voice Work within Educational Setting. Teaching, Learning and Sharing Music Therapy (Rīga: RSU, 2015)

[9] J. Bedics, The Handbook of Dialectical Behavior Therapy: Theory, Research, and Evaluation (Academic Press, 2020) 